\title{
Brief Review of Electron Collision Studies of Molecules Relevant to Plasma
}

\author{
Received September 8, 2020; accepted October 22, 2020
}

\author{
Dhanoj Gupta* \\ Department of Particle Physics and Astrophysics, Weizmann Institute of Science, Rehovot-7610001, Israel
}

*Corresponding author E-mail: dhanojsanjay@gmail.com

\begin{abstract}
A brief review of the electron collision studies of perfluorocarbons and $\mathrm{SF}_{6}$ relevant to plasma is presented. The use of these gases in various applications of plasma is highlighted, and their possible replacement with gases that have a low global warming potential is suggested. The results for a few simple fluorocarbons are presented, i.e., $\mathrm{C}_{2} \mathrm{~F}_{2}, \mathrm{C}_{3} \mathrm{~F}_{4}$, and $\mathrm{C}_{4} \mathrm{~F}_{6}$ for elastic scattering and $\mathrm{C}_{2} \mathrm{~F}_{6}$ for ionization, and the requirement for further investigation is highlighted. This review is not extensive; however, it presents an important step towards understanding the lack of cross-section data for numerous fluorocarbon molecules/radical species. In addition, it highlights the requirement for the detailed study of fluoroketones and fluoronitriles, which are possible substitutes for $\mathrm{SF}_{6}$ for various electron collisional processes other than ionization.
\end{abstract}

Keywords: Electron collision, Perfluorocarbons, Cross-section data, Plasma

\section{Introduction}

The collisions of electrons with atoms, molecules, ions, and surfaces are of fundamental importance in low-temperature plasmas (LTPs), with numerous applications in plasma science and technologies. LTPs represent a unique state of matter consisting of neutral atoms and molecules, radicals, ions, electrons, and excited states. They are used in the semiconductor industry for etching, depositing materials, synthesizing nanomaterials, and cleaning reaction chambers and in the field of plasma medicine [1]. Electron collision data are important in the fields of astrophysics, astrochemistry, aeronomy, radiation physics, gas discharge, electron beam lasers, and plasma processing devices for auroras and solar plasma [2]. Plasma-wall interactions are one of the major challenges in the realization of plasma reactors. These interactions are important for the physical and chemical processes in all plasmas with technological applications. Perfluorocarbons (PFCs) are extensively used as feedstock gases for various applications in plasma processing [3,4]. PFC gases, such as $\mathrm{CF}_{4}, \mathrm{C}_{2} \mathrm{~F}_{6}$, and $\mathrm{C}_{3} \mathrm{~F}_{8}$, have been widely used for plasma etching applications [3]. $\mathrm{SF}_{6}$ is widely used in high-voltage gas-insulated switchgears and gas-insulated lines [5] and as an etchant [6]. However, the global warming potential (GWP) of $\mathrm{SF}_{6}$ is 22800 times larger than that of $\mathrm{CO}_{2}$, and it is extremely difficult to decompose in the atmosphere [7]. This has led to interest in finding a suitable replacement for this gas. Moreover, owing to the requirement of the Kyoto Protocol [8] for the reduced emission of PFCs and $\mathrm{SF}_{6}$, research is being actively conducted on new gases with a low GWP, which can be suitable substitutes for existing plasma gases in various plasma applications. Hence, it is desirable to find alternative gases that are environment friendly with a relatively low GWP but with a potential similar to $\mathrm{SF}_{6}$ or other currently used PFCs. For this purpose, the detailed electron collision studies of possible substitute gases at the molecular level is important at energies ranging from $0-100 \mathrm{eV}$. In LTPs $(3-5 \mathrm{eV})$, the energy of electrons can reach up to $100 \mathrm{eV}$. Hence, the collision cross-section data in the range of 3-100 eV are important. Moreover, to experimentally analyze electron heating mechanisms $[9,10]$, scattering and excitation crosssection data are required up to a minimum of $25 \mathrm{eV}$ but desirable up to a maximum of $100 \mathrm{eV}$.

The literature survey shows that there is still a lack of electron collision cross-section data for numerous PFCs and their fragments. The ionization cross sections $\left(Q_{i o n}\right)$ for various $P F C s$, such as $\mathrm{CF}, \mathrm{CF}_{2}$, $\mathrm{CF}_{3}, \mathrm{C}_{2} \mathrm{~F}_{4}, \mathrm{C}_{2} \mathrm{~F}_{6}, \mathrm{C}_{3} \mathrm{~F}_{6}, \mathrm{C}_{3} \mathrm{~F}_{8}, \mathrm{C}_{4} \mathrm{~F}_{6}, \mathrm{C}_{4} \mathrm{~F}_{8}$, and $\mathrm{c}_{-} \mathrm{C}_{5} \mathrm{~F}_{8}$, have been measured using various experimental techniques [11-24]. Tarnovsky et al. [25] have measured the absolute cross section for the electron impact ionization and dissociative ionization of $\mathrm{C}_{2} \mathrm{~F}_{5}$ radicals from a threshold to $200 \mathrm{eV}$ using the fast-neutral-beam technique. The theoretical predictions $[11-15,26,27]$ for the above species have been made using the binary-encounter Bethe (BEB) [28,29], Deutsch-Mark (DM) $[30,31]$ and complex scattering potential-ionization contribution (CSP-ic) [32,33] methods, and they have shown reasonable agreement with experimental measurements. In recent years, there has been an increase in the research on PFCs for various electron collision processes with the objective of their quantifying cross sections. A complete study of $Q_{\text {ion }}$ has been performed for $\mathrm{C}_{2} \mathrm{~F}_{\mathrm{x}}(\mathrm{x}=1-6), \mathrm{C}_{3} \mathrm{~F}_{\mathrm{x}}(\mathrm{x}=1-8)$ [34], and $\mathrm{C}_{4} \mathrm{~F}_{\mathrm{x}}(\mathrm{x}=1-8)$ [35] neutral and radical species using the $\mathrm{BEB}$ method. The BEB and CSP-ic methods are briefly described in Section 2.

The literature survey for the low and intermediate energies for electron scattering elastic, differential, momentum, excitation, and total cross sections for PFCs shows the lack of complete cross-section data. Various elastic and total cross sections for PFCs and $\mathrm{SF}_{6}$ have been experimentally measured [36-52]. Szmytkowski and Możejko have compiled the measurements of the total cross sections from a 
range of molecules from 2009-2019 [53]. The low and intermediate energies cross-section calculations for various collision processes for several fluorocarbons have been theoretically predicted [54-59]. In recent years, the scarcity of cross-section data for simple fluorocarbons has led to studies on the low-energy cross section of fluorocarbons, such as $\mathrm{C}_{2} \mathrm{~F}_{2}$ [60], $\mathrm{C}_{3} \mathrm{~F}_{4}$ [61], and $\mathrm{C}_{4} \mathrm{~F}_{6}$ isomers [62], for various elastic and inelastic processes using the R-matrix method. At intermediate and high energies, differential and total cross sections have been computed using the single-center approach for $\mathrm{C}_{4} \mathrm{~F}_{6}$ isomers [63].

Goswami and Antony [64] have recently calculated cross-section for elastic and inelastic processes for an extensive range of energies for $\mathrm{SF}_{6}$ using the R-matrix and spherical complex optical potential (SCOP) $[32,33]$ methods. They have provided detailed references for various cross-section studies on $\mathrm{SF}_{6}$ in their article; hence, readers are directed to their article for more information about $\mathrm{SF}_{6}$. In the aspect of finding potential substitutes for $\mathrm{SF}_{6}$, fluoroketones and fluoronitriles have been extensively studied over the past few years owing to their low GWP compared to $\mathrm{SF}_{6}$ [65-68]. These studies have focused on the insulation properties of these gases under different conditions. Furthermore, these gases have received considerable attention for the study of electron impact ionization because this is an important parameter for examining electron avalanche and gas breakdown mechanisms. Wang et al. [7] have calculated the total $Q_{\text {ion }}$ of fluoroketones $\left(\mathrm{C}_{5} \mathrm{~F}_{10} \mathrm{O}\right.$ and $\left.\mathrm{C}_{6} \mathrm{~F}_{12} \mathrm{O}\right)$ and fluoronitriles $\left(\mathrm{C}_{3} \mathrm{~F}_{5} \mathrm{~N}\right.$ and $\mathrm{C}_{4} \mathrm{~F}_{7} \mathrm{~N}$ ) using the BEB method. Sinha et al. [69] have calculated the $Q_{\text {ion }}$ and electronic excitation cross section for $\mathrm{C}_{3} \mathrm{~F}_{6} \mathrm{O}, \mathrm{C}_{4} \mathrm{~F}_{8} \mathrm{O}, \mathrm{C}_{5} \mathrm{~F}_{10} \mathrm{O}$, $\mathrm{C}_{6} \mathrm{~F}_{12} \mathrm{O}$, and $\mathrm{C}_{4} \mathrm{~F}_{7} \mathrm{~N}$ using the CSP-ic method from the ionization threshold to $5000 \mathrm{eV}$. Wang et al. [70] have calculated the $Q_{\text {ion }}$ for $\mathrm{C}_{5} \mathrm{~F}_{10} \mathrm{O}$ and $\mathrm{C}_{6} \mathrm{~F}_{12} \mathrm{O}$ using the DM method. Xiong et al. [71] have calculated the $Q_{\text {ion }}$ for $\mathrm{C}_{5} \mathrm{~F}_{10} \mathrm{O}$ and $\mathrm{C}_{4} \mathrm{~F}_{7} \mathrm{~N}$ using the modified $\mathrm{DM}$ method. However, there are no studies on the elastic, excitation, differential, momentum transfer, and total cross sections for these species, which may be important for improving the understanding of these gases as potential substitutes for $\mathrm{SF}_{6}$. In addition, it may be interesting to investigate larger PFCs, such as $c-\mathrm{C}_{5} \mathrm{~F}_{8}, c-\mathrm{C}_{6} \mathrm{~F}_{8}, \mathrm{C}_{7} \mathrm{~F}_{8}$, $\mathrm{C}_{7} \mathrm{~F}_{14}$, and $\mathrm{c}-\mathrm{C}_{10} \mathrm{~F}_{8}$, as potential substitutes for $\mathrm{SF}_{6}$ and other PFCs with higher GWP. One of the primary motivations of the present review is to highlight the requirement for the detailed investigation of fluoroketones, fluoronitriles, and larger PFCs along with their fragment species and radicals for various electron collision processes that could be useful for plasma applications/modeling. A recommended set of databases for electron collision studies for multiple PFCs, such as $\mathrm{CF}_{4}, \mathrm{C}_{2} \mathrm{~F}_{6}, \mathrm{C}_{3} \mathrm{~F}_{8}, \mathrm{c}-\mathrm{C}_{4} \mathrm{~F}_{8}$, and $\mathrm{SF}_{6}$, has been provided by Christophorou and Olthoff [72-77]. A recent recommended set of data for electron collision for plasma relevant molecules has been provided by Yoon $e t$ al. [78] and Cho et al. [79].

In the current scenario, it is widely recognized that there are new technological advances in plasma processing and the utilization of plasmas in general, ranging from plasma medicine to material processing. These developments are based on the manipulation of plasma properties. This highlights the requirement for a detailed understanding of the atomic and molecular processes within plasmas. It is well known that theoretical calculations are important for providing data over a comprehensive range of energies [80]. Even though there is active research worldwide on the experimental determination of electron collision cross sections for several atoms/molecules/radicals, the data for numerous other important targets are still unknown [81]. In the next section, a brief description of the theoretical methods used by the author is presented along with recent results obtained using each method.

\section{Theoretical methods}

\subsection{R-matrix method for low-energy calculations ( $0-15 \mathrm{eV})$}

There are various theoretical methods for studying low-energy electron-molecule collisions. This subsection presents a brief overview of the ab-initio R-matrix method [82,83], which is used by the author for numerous calculations. This is the most widely used approach for calculating electron atom/molecule collision cross sections at low energies. There are other ab-initio methods, such as the Schwinger multichannel [84] and Kohn variation [85] methods, which can be used to calculate cross sections at low energies. All three methods are based on the variation principle, and they provide reliable cross sections for numerous systems. Furthermore, the results obtaining using each method with the same target and scattering models exhibit good agreement. The molecular convergent close-coupling [86] method based on the momentum-space formulation of the close-coupling theory is an emerging technique for calculating the electron collision cross sections of atoms and molecules at low energies.

The UK polyatomic R-matrix codes [87] have been implemented in the Quantemol-N software [88], which can be used by specialists and nonspecialists with a background in scattering theory. Quantemol$\mathrm{N}$ has been used for several years for successfully calculating various low-energy cross sections for a variety of molecules [89-101]. The fixed nuclei approximation has been employed in all calculations performed by the author. The basis of the R-matrix method is the division of a configuration space into an inner region and outer region. The inner region should be selected such that it contains the wave function of a target, where the center of mass of the target coincides with the origin of the coordinate system. The interaction potentials originating from the static, exchange, polarization, and correlation between the target and projectile must be included in the inner region. The advantage of the inner region problem is that a precise solution can be obtained using quantum chemistry codes. The inner region problem is energy independent, and hence, it must be solved only once. This makes the R-matrix method computationally affordable and easy to use. All target properties are calculated in the inner region.

The wave function constructed inside the inner region for the $(N+1)$ electron system is given by a close-coupling [102] approximation,

$$
\begin{aligned}
\psi_{k}^{N+1}= & A \sum_{i j} a_{i j k} \Phi_{i}^{N}\left(x_{1}, \cdots, x_{N}\right) u_{i j}\left(x_{N+1}\right) \\
& +\sum_{i} b_{i k} \chi_{i}^{N+1}\left(x_{1}, \cdots, x_{N+1}\right)
\end{aligned}
$$

where $A$ is an antisymmetrization operator, which ensures that Pauli's exclusion principle is obeyed by a scattering electron, $\Phi_{i}^{N}$ is the wave function of the $i^{\text {th }}$ target state, and $x_{N}$ is the spatial and spin coordinate of the $N^{\text {th }}$ target electron. $u_{i j}$ denotes the continuum orbitals used to represent the scattering electron. $a_{i j k}$ and $b_{i k}$ are variational coefficients determined by the diagonalization of the Hamiltonian matrix. In Eq. (1), the first summation runs over the target and continuum states. It accounts for one electron in the continuum state and the remaining electrons in the target states; this is known as a 'target + continuum' configuration. The electron correlations and polarization effects are 
accounted for by the second summation, where $\chi_{i}^{N+1}$ are referred to as the $L^{2}$ configurations. These are multicenter quadratically integrable functions constructed by placing all $N+1$ electrons in target molecular orbitals (MOs).

A set of MOs is constructed from occupied and virtual target MOs using the Hartree-Fock self-consistent-field calculation augmented with Gaussian type orbitals and the continuum orbitals of Faure et al. [103]. The calculation is performed with the continuum orbitals up to $g$ partial waves. The effect of correlation/polarization can be improved by including more excited states in the calculations. This improvement is indicated by the shifting of resonance positions to lower energies. The important aspect of the problem is to achieve the convergence of results. Once convergence is achieved, further improvement in the correlation/polarization effects has a minimal effect on results. After computing the target properties inside the inner region, the solution of the inner region is propagated to the boundary, where the R-matrix connects the inner region solution to the outer region. Depending on the size of the target, the inner region radius varies from $10 a_{0}$ to $15 a_{0}$ or a larger radius so that the molecular charge density of the target is fully contained inside this radius in general. In the R-matrix calculations for $\mathrm{C}_{2} \mathrm{~F}_{2}$ and $\mathrm{C}_{3} \mathrm{~F}_{4}$, the inner region radius is chosen to be $10 a_{0}$, whereas for $\mathrm{C}_{4} \mathrm{~F}_{6}$ isomers it is kept at $12 a_{0}$. In the outer region, the R-matrix is matched with asymptotic functions obtained from a Gailitis expansion [104] by extending it outwards up to $100 a_{0}$ to the asymptotic region. The problem becomes simpler in the outer region because the scattering electron is quite far from the target charge cloud, where the exchange and correlation effects are negligible. Here, only the long-range multipolar interactions between the projectile and target must be considered. However, energy dependence is applicable in this region. Asymptotic $K$-matrices are obtained by integrating the coupled single-center equations that describe the scattering. These $K$-matrices are used to deduce all observables, such as eigenphases, cross sections, and resonances, using the $T$-matrices defined in the terms of the $K$-matrices, as follows:

$$
T=\frac{2 i K}{1-i K}
$$

Moreover, differential cross sections and momentum transfer cross sections can be acquired using the $K$-matrices in the POLYDCS program developed by Sanna and Gianturco [105]. Subsequently, the RESON resonance detection program [106] can be used for detecting and performing Breit-Wigner fits [107] to resonances. The resonances are an important feature of low-energy collision studies.

\subsection{SCOP and CSP-ic methods for intermediate to high energy calculations ( $10 \mathrm{eV}$ to $5 \mathrm{keV}$ )}

The SCOP and CSP-ic methods are widely used theoretical formalisms for calculating elastic and inelastic cross sections at intermediate to high energies. The total cross section is the sum of elastic and inelastic cross sections. These methods have been successfully used to calculate various electron collision cross section for atoms [108-114] and molecules [115-124] at intermediate to high energies. In addition, they have been adapted to study positron collisions with atoms and molecules [125]. In the SCOP method, complex optical potential $\left(V_{\text {opt }}\right)$ is formulated for a projectile-target system consisting of real $\left(V_{R}\right)$ and imaginary $\left(V_{I}\right)$ parts. The potential is spherically symmetric such that it depends on radial distance ' $r$ ' and incident energy $E_{i}$, and it is given by

$$
V_{\text {opt }}\left(r, E_{i}\right)=V_{R}(r)+i V_{I}\left(r, E_{i}\right)
$$

The first term of Eq. (3) accounts for all elastic processes, and the second term represents absorption processes, which account for the loss of flux into various inelastic channels. Real potential consists of static $\left(V_{s t}\right)$, exchange $\left(V_{e x}\right)$, and polarization $\left(V_{p}\right)$ potentials, and it is given by

$$
V_{R}\left(r, E_{i}\right)=V_{s t}(r)+V_{e x}\left(r, E_{i}\right)+V_{p}\left(r, E_{i}\right)
$$

The static potential and charge density of a target are obtained from the parameterized Roothan-Hartree-Fock wavefunction of the Cox and Bonham parameters [126]. Exchange potential is obtained from the parameter-free Hara [127] free electron gas exchange model, and the model potential of Zhang et al. [128] is used for polarization and correlation interaction. The imaginary term is given by the model potential of Staszewska et al. [129]. The improved or advanced versions of these potentials can be found in literature, and they can be easily used in the SCOP method to improve the quality of results.

Once the complete interaction potential given by Eq. (3) is obtained, the Schrödinger equation is solved using the partial wave approximation to obtain the complex phase shifts $\left(\delta_{l}\right)$ for each partial wave using the Numerov method. These phase shifts contain all relevant information regarding projectile-target interactions. The obtained phase shifts are used to calculate elastic, inelastic, and momentum transfer cross sections, which are expressed as follows [130]:

$$
\begin{gathered}
Q_{e l}\left(E_{i}\right)=\frac{\pi}{k^{2}} \sum_{l=0}^{\infty}(2 l+1)\left|\eta_{l} \exp \left(2 i \operatorname{Re} \delta_{l}\right)-1\right|^{2} \\
Q_{\text {inel }}(k)=\frac{\pi}{k^{2}} \sum_{l=0}^{\infty}(2 l+1)\left(1-\eta_{l}^{2}\right) \\
Q_{m t c s}(k)=\frac{4 \pi}{k^{2}} \sum_{l=0}^{\infty}(l+1) \sin ^{2}\left[\delta_{l+1}(k)-\delta_{l}(k)\right]
\end{gathered}
$$

Here, $k$ is a wave vector. The "inelasticity" or "absorption" factor for each partial wave, ' $l$ ', is given by

$$
\eta_{l}=\exp \left(-2 \mathbf{I m} \delta_{l}\right)
$$

The sum of elastic and inelastic cross sections from Eqs. (5) and (6) provides the total cross section, which is expressed as

$$
Q_{T}(k)=\frac{2 \pi}{k^{2}} \sum_{l=0}^{\infty}(2 l+1)\left[1-\eta_{l} \cos \left(2 i \operatorname{Re} \delta_{l}\right)\right]
$$

The detailed derivation of the equations are provided in [130].

The inelastic cross section calculated using the SCOP method can be utilized to obtain $Q_{i o n}$ by employing the CSP-ic method. As $Q_{\text {inel }}$ is the sum of all allowed electronic excitation and ionization cross sections, it can be written as 


$$
Q_{\text {inel }}\left(E_{i}\right)=Q_{\text {exc }}\left(E_{i}\right)+Q_{\text {ion }}\left(E_{i}\right)
$$

where the first term represents the total excitation cross section for all dipole-allowed electronic transitions and the second term represents all ionization processes (single, double, inner shell, etc.) induced by a projectile electron. The contribution of excitation decreases as the contribution of ionization increases with incident energies. $Q_{i o n}$ is derived by defining an energy dependent ratio of $Q_{\text {ion }} / Q_{\text {inel }}$. This subsection provides only a brief description of the CSP-ic method; the detailed description can be found in previous works [131-134].

\subsection{BEB method for total ionization cross section}

The BEB method is combination of the Bethe theory and Mott cross section. Kim and Rudd [28] and Hwang et al. [29] have combined these two theories for the dipole interaction between incident and target electrons at higher incident energies accounting for Bethe theory and the collision of two free electrons accounts for the Mott theory. The BEB method can provide cross sections for a wide range of targets from atoms to molecules, and the results of the method are in reasonable agreement with experimental data. The main inputs for the BEB method are the kinetic and binding energies of each target orbital. The total $Q_{\text {ion }}$ of a target is obtained by adding the $Q_{i o n}$ of each target orbital. $Q_{i o n}$ is calculated using the following equations:

$$
\sigma_{B E B}=\frac{S}{t+u+1}\left[\frac{\ln t}{2}\left(1-\frac{1}{t^{2}}\right)+1-\frac{1}{t}-\frac{\ln t}{t+1}\right]
$$

where

$$
t=\frac{T}{B} ; u=\frac{U}{B} ; s=4 \pi a_{0}^{2} N\left(\frac{R}{B}\right)^{2}
$$

Here, $B$ and $U$ are the binding and kinetic energies of an electron on a given $\mathrm{MO}$, respectively, $T$ is the incident energy of the electron, $N$ is the occupation number of electrons on the given MO, $R$ is the Rydberg energy, and $a_{0}$ is the Bohr radius.

A recent article by Karwasz et al. [135] provides a fairly detailed description of the BEB and DM methods used for calculating $Q_{i o n}$ for fluoromethanes. The DM method is widely used for obtaining the $Q_{\text {ion }}$ of atoms/molecules/clusters, and it requires the knowledge of the partial occupancies of MOs by electrons from constituent atoms.

\section{Results and discussion}

This section discusses the recent results obtained by Gupta et al. for $\mathrm{C}_{2} \mathrm{~F}_{2}$ [60], $\mathrm{C}_{3} \mathrm{~F}_{4}$ [61], and $\mathrm{C}_{4} \mathrm{~F}_{6}$ isomers [62] for elastic and inelastic scattering at low energies and $\mathrm{C}_{2} \mathrm{~F}_{6}[34]$ for ionization.

Figure 1(a) shows the application of the R-matrix and SCOP methods at low, intermediate, and high energies to calculate the elastic cross section, as studied by Gupta et al. [60]. The result is shown for $\mathrm{C}_{2} \mathrm{~F}_{2}$. The R-matrix method is employed up to an energy of $12 \mathrm{eV}$, after which the SCOP method is applied at intermediate and higher energies. A smooth transition between the two methods is observed at approximately $12 \mathrm{eV}$. A $\pi^{*}$ shape resonance for $\mathrm{C}_{2} \mathrm{~F}_{2}$ is detected at $5.86 \mathrm{eV}$, and a sharp feature in the elastic cross section is observed at the same energy. As there are no other results available for $\mathrm{C}_{2} \mathrm{~F}_{2}$, the
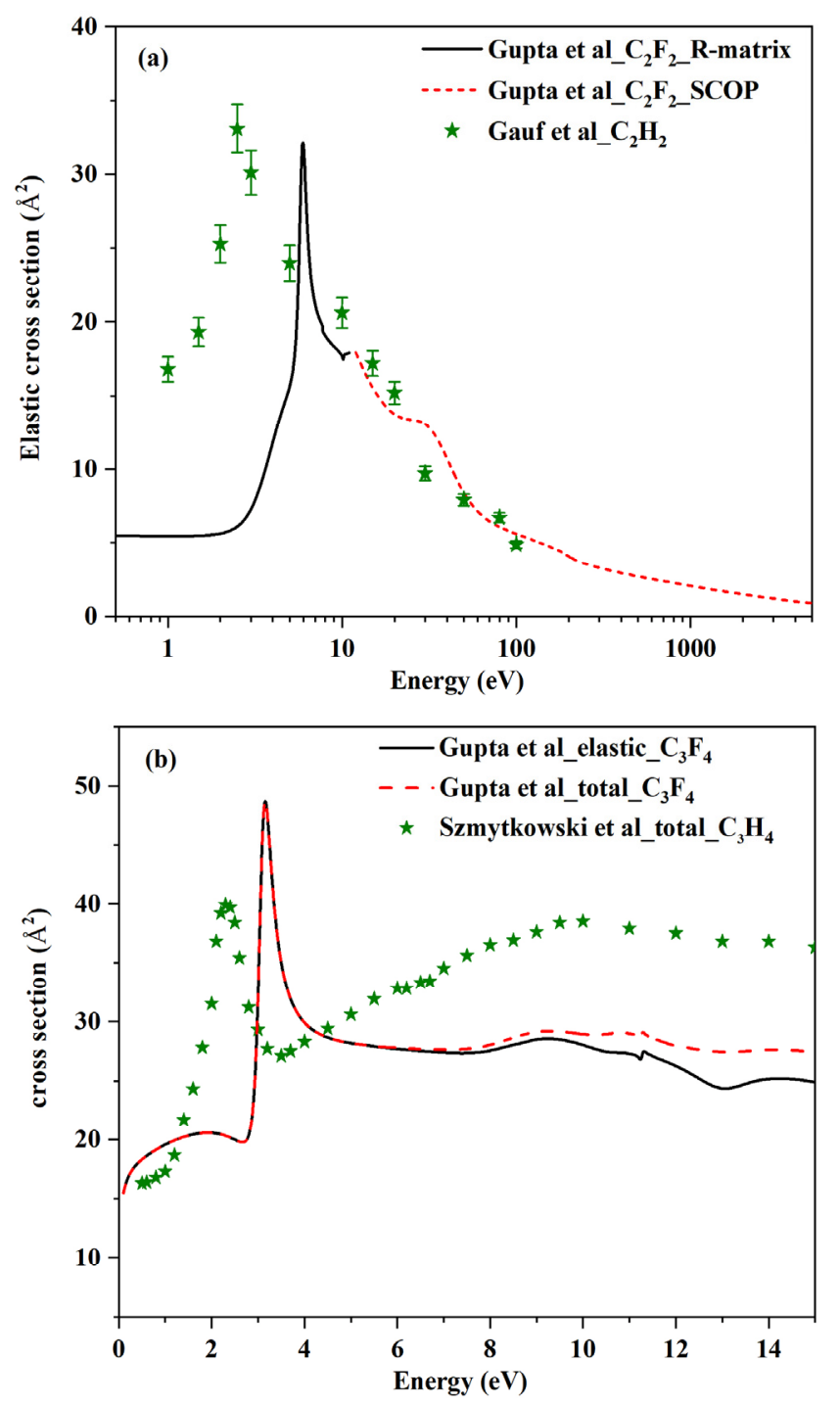

Figure 1. (a) Elastic scattering cross section for $\mathrm{e}-\mathrm{C}_{2} \mathrm{~F}_{2}$ from low $(0.1 \mathrm{eV})$ to high (5 $\mathrm{keV}$ ) energies calculated using the R-matrix and spherical complex optical potential (SCOP) methods [60] and comparison with experimental data of Gauf et al. for $\mathrm{C}_{2} \mathrm{H}_{2}$ [136]. (b) Elastic and total cross section for $\mathrm{C}_{3} \mathrm{~F}_{4}$ [61] calculated using the R-matrix method and comparison with the experimental data of Szmytkowski et al. for $\mathrm{C}_{3} \mathrm{H}_{4}$ [137].

aforementioned results have been compared with those obtained by Gauf et al. [136] for the $\mathrm{C}_{2} \mathrm{H}_{2}$ molecule, whose structure is similar to that of $\mathrm{C}_{2} \mathrm{~F}_{2}$. The effect of fluorination is clearly seen in the elastic cross section, where the shape resonance for $\mathrm{C}_{2} \mathrm{~F}_{2}$ is shifted to higher energies compared to $\mathrm{C}_{2} \mathrm{H}_{2}$. Figure 1 (b) compares the total and elastic cross sections obtained by Gupta et al. [61] for $\mathrm{C}_{3} \mathrm{~F}_{4}$ with the experimental results of $\mathrm{C}_{3} \mathrm{H}_{4}$ [137], in the absence of any other data for $\mathrm{C}_{3} \mathrm{~F}_{4}$. Similar to $\mathrm{C}_{2} \mathrm{~F}_{2}$, the shape resonance for $\mathrm{C}_{3} \mathrm{~F}_{4}$ is shifted to higher energies compared to $\mathrm{C}_{3} \mathrm{H}_{4}$. The shifting of resonances to higher energies may be due to the shortening of the $\mathrm{C}-\mathrm{C}$ bond in the case of $\mathrm{C}_{2} \mathrm{~F}_{2}$ and $\mathrm{C}_{3} \mathrm{~F}_{4}$ compared to $\mathrm{C}_{2} \mathrm{H}_{2}$ and $\mathrm{C}_{3} \mathrm{H}_{4}$. A detailed explanation for such behavior is given in our previous articles [60,61]. It should be noted that there are no experimental or theoretical data available for such small fluorocarbon species. Moreover, the dis- 

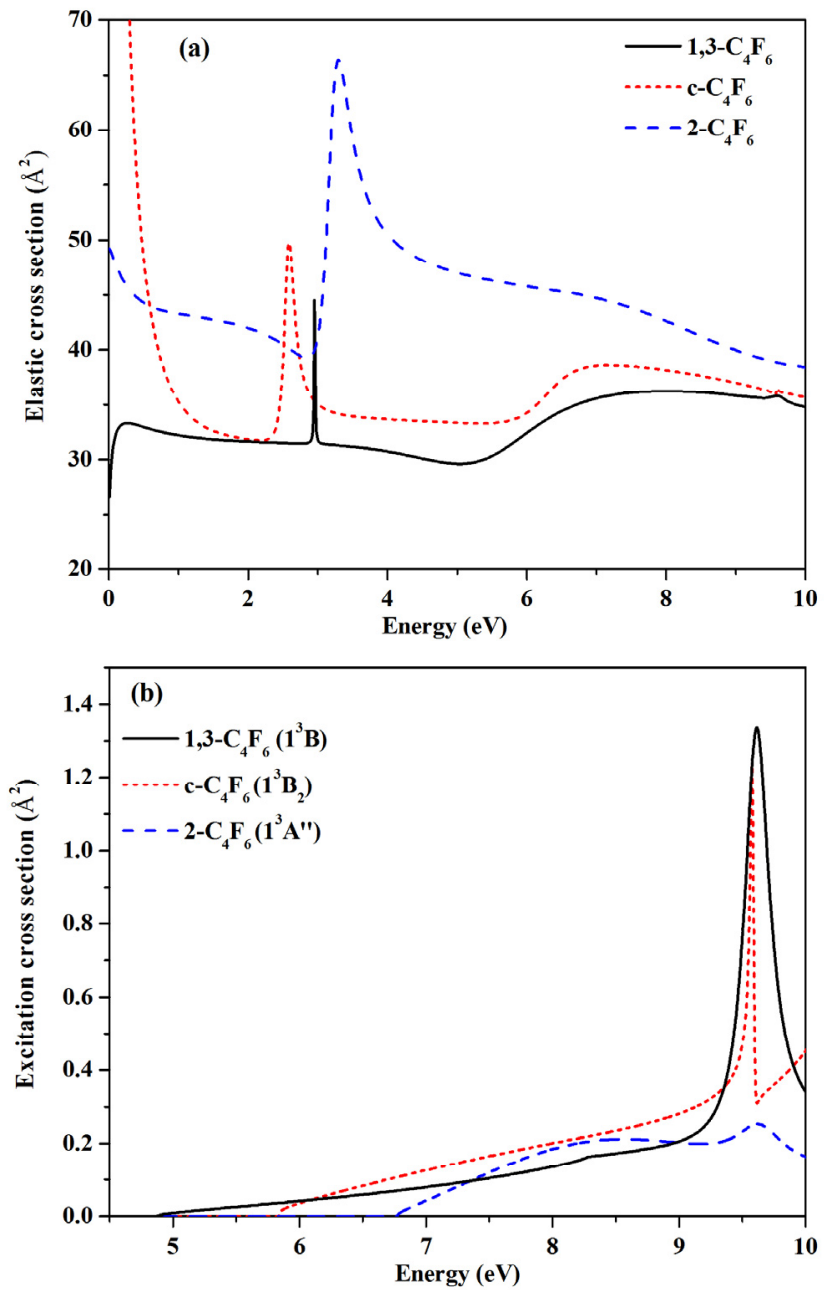

Figure 2. Isomer effect in the (a) elastic cross section and (b) first excitation cross section of $1,3-\mathrm{C}_{4} \mathrm{~F}_{6}, \mathrm{c}-\mathrm{C}_{4} \mathrm{~F}_{6}$, and $2-\mathrm{C}_{4} \mathrm{~F}_{6}$ in a multistate configuration interaction $(\mathrm{Cl})$ calculation. Solid line: Present $1,3-\mathrm{C}_{4} \mathrm{~F}_{6}$; Short dashed line: Present $\mathrm{c}_{-} \mathrm{C}_{4} \mathrm{~F}_{6}$; Dashed line: Present 2- $\mathrm{C}_{4} \mathrm{~F}_{6}$ (reproduced from Gupta et al., Phys. Plasmas 25, 063504 (2018) with permission from AIP publishing) [62].

sociation of stable parent fluorocarbon molecules, such as $\mathrm{CF}_{4}, \mathrm{C}_{2} \mathrm{~F}_{6}$, $\mathrm{C}_{3} \mathrm{~F}_{8}$, and $\mathrm{C}_{4} \mathrm{~F}_{8}$, in plasma by electron impact leads to the formation of numerous such reactive species of $\mathrm{C}_{\mathrm{x}} \mathrm{F}_{\mathrm{y}}(\mathrm{x}=1-3, \mathrm{y}=1-7)$. Hence, studying the microscopic properties of such fragment species and radicals is important for fluorocarbon plasmas [25]. As highlighted in the introduction, cross sections in a range of $0-100 \mathrm{eV}$ are desirable for LTPs. The calculation of cross sections over a wide energy range using two different methods for $\mathrm{C}_{2} \mathrm{~F}_{2}$ shows that such a hybrid methodology can easily be applied to other such cases. The study of these simple fluorocarbons, for which data are not available, highlights the requirement for further investigation into these systems.

Figure 2 shows the results for the R-matrix calculation of the elastic and excitation cross sections for the three isomers of $\mathrm{C}_{4} \mathrm{~F}_{6}$, i.e., 1,3- $\mathrm{C}_{4} \mathrm{~F}_{6}, \mathrm{c}-\mathrm{C}_{4} \mathrm{~F}_{6}$, and $2-\mathrm{C}_{4} \mathrm{~F}_{6}$. Even though the molecular formulae for all isomers are the same, their elastic scattering cross sections are quite different below $8 \mathrm{eV}$ as depicted in Fig. 2(a) owing to the different molecular geometry of the targets. The shape resonance is detected for all three isomers, $1,3-\mathrm{C}_{4} \mathrm{~F}_{6}, \mathrm{c}-\mathrm{C}_{4} \mathrm{~F}_{6}$, and $2-\mathrm{C}_{4} \mathrm{~F}_{6}$ at $2.95,2.57$ and 3.20 respectively. The experimental results of the elastic cross section

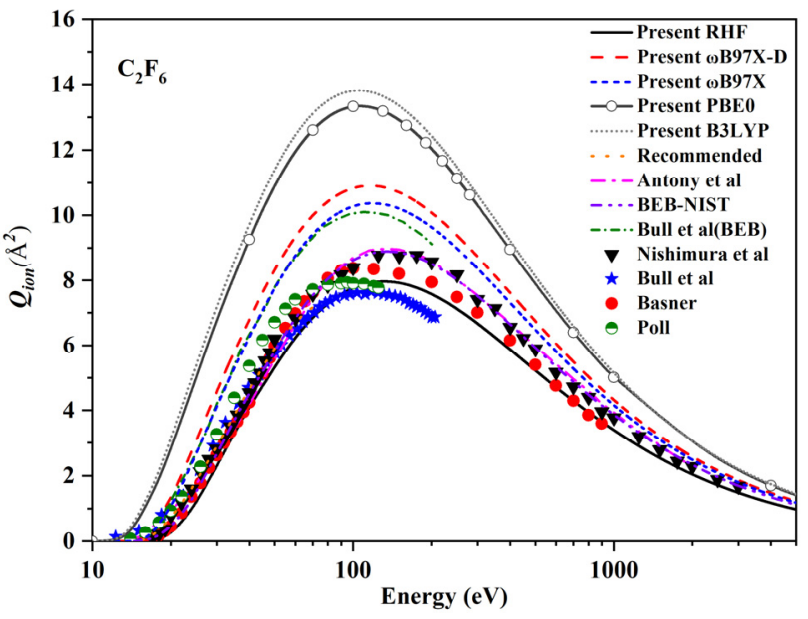

Figure 3. Total ionization cross section for $\mathrm{C}_{2} \mathrm{~F}_{6}$ in $\AA^{2}$ along with available comparisons. Solid line: Gupta et al. (restricted Hartree-Fock; RHF) [34]. Dashed line: Gupta et al. ( $\omega$ B97X-D) [34]; Short dashed line: Gupta et al. ( $\omega$ B97X) [34]; Line symbol: Gupta et al. [34] (PBE0); Short dotted line: Gupta et al. [34] (B3LYP); Dotted line: Recommended [73]; Dash-dot line: Antony et al. [26]; Dash-dot-dot line: binary-encounter Bethe (BEB)-NIST [138]; Short dash-dot line: Bull et al. (BEB) [14]; Triangle: Nishimura et al. [12]; Stars: Bull et al. [14]; Solid circle: Basner et al.[17]; Half circle: Poll and Meichsner [19] (adapted from Gupta et al., Eur. Phys. J. D 71, 88 (2017) with permission from the European Physical Journal) [34].

obtained by Hoshino et al. [45] do not indicate a resonance structure (not shown here). The comparison of the experimental data with theoretical R-matrix calculations is presented in the paper by Gupta et al. [62]. The cross section for $2-\mathrm{C}_{4} \mathrm{~F}_{6}$ is the largest, which may be owing to its larger molecular structure. Moreover, the isomer effect is quite strong below $8 \mathrm{eV}$, and it becomes weaker as incident energy increases.

Figure 2(b) depicts the excitation cross section of the first excited state of the three isomers. The thresholds for the first excitation energy of $1,3-\mathrm{C}_{4} \mathrm{~F}_{6}, \mathrm{c}-\mathrm{C}_{4} \mathrm{~F}_{6}$, and $2-\mathrm{C}_{4} \mathrm{~F}_{6}$ are at $4.88,5.84$, and 6.74 $\mathrm{eV}$ for the ${ }^{3} \mathrm{~B},{ }^{3} \mathrm{~B}_{2}$ and ${ }^{3} \mathrm{~A}$ " states, respectively. The isomer effect is not sufficiently strong in the case of the electronic excitation cross section. The sharp feature is observed at approximately $9.6 \mathrm{eV}$ for $1,3-\mathrm{C}_{4} \mathrm{~F}_{6}$ and $2-\mathrm{C}_{4} \mathrm{~F}_{6}$, which may be owing to the Feshbach resonances detected at the same energy range for these isomers. A recent study by Bharadvaja et al. [63] provides the differential and integral cross sections for these isomers at intermediate and high energies. $\mathrm{C}_{4} \mathrm{~F}_{6}$ is quite important for plasma applications/processing, and hence, its physical and chemical reference data and cross sections must be further investigated to completely understand its nature and characteristics.

Figure 3 shows the $Q_{\text {ion }}$ of $\mathrm{C}_{2} \mathrm{~F}_{6}$ calculated using the $\mathrm{BEB}$ method for various orbital energies by Gupta et al. [34]. $\mathrm{C}_{2} \mathrm{~F}_{6}$ has been experimentally and theoretically studied in detail. The data of Gupta et al. are further compared with available experimental and theoretical data. Orbital energies are calculated at various levels of theoretical approximation using the Gaussian 09 [139] package. Bull et al. [14] have recently suggested that the orbital parameters employed in the calculation of $Q_{i o n}$ using the BEB method should be obtained using a high level of theoretical approximation. They have utilized the partial third-order electron propagator theory (P3-EPT) level of approximation for obtaining orbital parameters for binding energies less than $20 \mathrm{eV}$. In BEB calculations, the orbital energies of lower orbitals are the most important and have the maximum contribution to the $Q_{i o n}$. However, 
for a few fluorocarbons, the results obtained using such orbital parameters do not agree better with experimental data compared to Hartree-Fock (HF) orbitals and overestimate experimental results. For $\mathrm{C}_{2} \mathrm{~F}_{6}$, Gupta et al. [34] have shown that the results obtained using the density functional theory (DFT) $(\omega \mathrm{B} 97 \mathrm{X})$ functional for orbital binding and kinetic energies are in reasonable agreement with the P3-EPT calculations of Bull et al. [14], with slight variations at the peak of the cross section. The results obtained using the DFT ( $\omega$ B97X-D) functional are slightly higher than those obtained using the DFT ( $\omega$ B97X) functional, which may be owing to the inclusion of dispersion in the functional. The DFT (B3LYP) and DFT (PBE0) functionals provide low binding energies. Hence, the cross sections obtained using these functionals are large compared to other results. The $Q_{\text {ion }}$ calculated using the BEB method is extremely sensitive to the binding energy calculations for lower orbitals.

The BEB results of Gupta et al. [34] are also compared with the experimental data of Nishimura et al. [12], Bull et al. [14], Basner et al. [17], and Poll and Meichsner [19], the theoretical data of Antony et al. [26] and Bull et al. [14], and the cross sections recommended by Chirstophorou and Olthoff [73]. The $Q_{\text {ion }}$ from NIST [138] calculated using the BEB method is also included for comparison. The restricted HF (RHF) results of Gupta et al. [34] show excellent agreement with all experimental data from the threshold to the peak. In addition, they show good agreement with the experimental data of Basner et al. [17] at higher energies. Furthermore, the RHF results of Gupta et al. [34] are in good agreement with all other theoretical data below $80 \mathrm{eV}$ and less than the theoretical data above $80 \mathrm{eV}$. The theoretical data of Antony et al. [26] and the BEB data from NIST [138] show good agreement with the experimental data of Nishimura et al. [12]. Antony et al. [26] have used the CSP-ic method for calculating $Q_{\text {ion }}$, and the results agree well with the RHF BEB data of Gupta et al. [34]. Moreover, the CSP-ic method is effective for calculating $Q_{i o n}$ and provides the necessary reference to compare data with the BEB and DM methods. This enables us to find the consistent or recommended sets of data for $Q_{i o n}$. The studies by Gupta et al. for the ionization of $\mathrm{C}_{2} \mathrm{~F}_{\mathrm{x}}(\mathrm{x}=1-6), \mathrm{C}_{3} \mathrm{~F}_{\mathrm{x}}(\mathrm{x}=1-8)$ [34], and $\mathrm{C}_{4} \mathrm{~F}_{\mathrm{x}}(\mathrm{x}=1-8)$ [35] neutral and radical species have shown that the use of the DFT $(\omega \mathrm{B} 97 \mathrm{X})$ functional may be suitable for fluorocarbon containing species when compared with recent experimental and theoretical data in general. Hence, such functionals can be used for further studies of ionization.

\section{Conclusion}

A brief review of the electron collision studies of perfluorocarbons and $\mathrm{SF}_{6}$ has been presented. The summary of the review is provided below.

- Sample theoretical results are presented for $\mathrm{C}_{2} \mathrm{~F}_{2}, \mathrm{C}_{3} \mathrm{~F}_{4}, \mathrm{C}_{2} \mathrm{~F}_{6}$, and $\mathrm{C}_{4} \mathrm{~F}_{6}$ isomers to show the application of the R-matrix, SCOP, CSP-ic, and BEB methods. These methods could be further utilized to study other systems where there is a requirement for data.

- The $Q_{i o n}$ of fluoroketones and fluoronitriles, which are considered as potential substitutes for $\mathrm{SF}_{6}$, has been extensively investigated. However, there is a lack of cross-section data for other collision processes such as elastic, excitation, and dissociation.

- The experimental investigation of PFCs, fluoroketones, and fluoronitriles with fluorine as one of the constituent atoms may be difficult owing to their reactive nature. Hence, theoretical predictions and calculations are required to meet the requirement of cross-section data for plasma modelers.

- It may be appropriate to further investigate larger PFC gases, such as $c-\mathrm{C}_{5} \mathrm{~F}_{8}, c-\mathrm{C}_{6} \mathrm{~F}_{8}, \mathrm{C}_{7} \mathrm{~F}_{8}, \mathrm{C}_{7} \mathrm{~F}_{14}$, and $c-\mathrm{C}_{10} \mathrm{~F}_{8}$, to find a potential replacement for fluorocarbon plasma gases with a high GWP.

- A systematic study of all PFCs, fluoroketones, and fluoronitriles, considering their physical and chemical properties and various collision cross sections, could be useful for various applications in plasma science and technology.

\section{Acknowledgements}

The author would like to thank the Weizmann Institute of Science, Israel, for the prestigious Dean of Faculty Fellowship and Prof. Daniel Zajfman and Dr. Oded Heber from the Weizmann Institute of Science for their support. The author would also like to thank his collaborators, Dr. Jung Sik-Yoon, Dr. Mi-Young Song, Dr. Deuk Chul Kwon, and Dr. Heechol Choi from National Fusion Research Institute, South Korea, Prof. Bobby Antony from the Indian Institute of Technology (Indian School of Mines) Dhanbad, India, and Dr. Suvam Singh from the Max Plank Institute for Nuclear Physics, Germany.

\section{References}

[1] I. Adamovich, S. D. Baalrud, A. Bogaerts, P. J. Bruggeman, M. Cappelli, V. Colombo, U. Czarnetzki, U. Ebert, J. G. Eden, P. Favia, et al., J. Phys. D: Appl. Phys. 50, 323001 (2017) and references therein.

[2] A. Zecca, G. Karwasz, S. Oss, R. Grisenti, and R. S. Brusa, J. Phys. B: At. Mol. Phys. 20, L133, (1987).

[3] L. G. Christophorou and J. K. Olthoff, Fundamental Electron Interactions with Plasma Processing Gases (Springer Science \& Business Media, Berlin, 2012).

[4] L. G. Christophorou, Electron-Molecule Interactions and Their Applications (Academic Press, Massachusetts, 2013).

[5] X. W. Li, H. Zhao, and A. B. Murphy, J. Phys. D: Appl. Phys. 51, 153001 (2018).

[6] T. T. N. Nguyen, M. Sasaki, H. Odaka, T. Tsutsumi, K. Ishikawa, and M. Hori, J. Appl. Phys. 125, 063304 (2019).

[7] F. Wang, Q. Dun, S. Chen, L. Zhong, X. Fan, and L. Li, IEEE Trans. Dielectr. Electr. Insul. 26, 1693 (2019).

[8] S. Oberthur, The Kyoto Protocol: International Climate Policy for the 21st Century (Springer, Berlin, 1999).

[9] S. Gu, H. J. Kang, D. C. Kwon, Y. S. Kim, Y. M. Chang, and C. W. Chung, Phys. Plasmas 23, 063506 (2016).

[10] J. H. Kim, D. C. Kwon, and C. W. Chung, J. Vac. Sci. Technol. B 38, 022801 (2020)

[11] V. Tarnovsky, P. Kurunczi, D. Rogozhnikov, and K. Becker, Int. J. Mass Spectrom. Ion Processes, 128, 181 (1993).

[12] H. Nishimura, W. M. Huo, M. A. Ali, and Y. K. Kim, J. Chem. Phys. 110, 3811 (1999).

[13] M. Bart, P. W. Harland, J. E. Hudson, and C. Vallance, Phys. Chem. Chem. Phys. 3, 800 (2001).

[14] J. N. Bull, M. Bart, C. Vallance, and P. W. Harland, Phys. Rev. A 88, 062710 (2013).

[15] J. N. Bull, P. W. Harland, and C. J. Vallance, Phys. Chem. A 116, 
767 (2012).

[16] J. A. Beran and L. Kevan, J. Phys. Chem. 73, 3866 (1969).

[17] R. Basner, M. Schmidt, E. Denisov, P. Lopata, K. Becker, and H. Deutsch, Int. J. Mass Spectrom. 214, 365 (2002).

[18] M. V. Kurepa, 3rd Cz. Conference on Electronics and Vacuum Transactions (1965).

[19] H. U. Poll and J. Meichsner, Contrib. Plasma Phys. 27, 359 (1987).

[20] C. Q. Jiao, A. Garscadden, and P. D. Haaland, Chem. Phys. Lett. 325, 203 (2000).

[21] H. Toyoda, M. Ito, and H. Sugai, Jpn. J. Appl. Phys. 36, 3730 (1997).

[22] C. Q. Jiao, A. Garscadden, and P. D. Haaland, Chem. Phys. Lett. 297, 121 (1998).

[23] C. Q. Jiao, C. A. DeJoseph Jr, R. Lee, and A. Garscadden, Int. J. Mass Spectrom. 274, 14 (2008).

[24] C. Q. Jiao, C. A. DeJoseph Jr, and A. Garscadden, J. Phys. D: Appl. Phys. 38, 1076 (2005).

[25] V. Tarnovsky, H. Deutsch, and K. Becker, J. Phys. B: At. Mol. Opt. Phys. 32, L573 (1999).

[26] B. K. Antony, K. N. Joshipura, and N. J. Mason, J. Phys. B: At. Mol. Opt. Phys. 38, 189 (2005).

[27] U. R. Patel, K. N. Joshipura, H. N. Kothari, and S. H. Pandya, J. Chem. Phys. 140, 044302 (2014).

[28] Y. K. Kim and M. E. Rudd, Phys. Rev. A 50, 3954 (1994).

[29] W. Hwang, Y. K. Kim, and M. E. Rudd, J. Chem. Phys. 104, 2956 (1996).

[30] D. Margreiter, H. Deutsch, M. Schmidt, and T. D. Märk, Int. J. Mass Spectrom. Ion Process. 100, 157 (1990).

[31] D. Margreiter, H. Deutsch, and T. D. Mark, Contr. Plasma Phys. 30, 487 (1990).

[32] K. N. Joshipura, M. Vinodkumar, C. G. Limbachiya, and B. K. Antony, Phys. Rev. A 69, 022705 (2004).

[33] K. N. Joshipura, M. Vinodkumar, B. K. Antony, and N. J. Mason, Eur. Phys. J. D 23, 81 (2003).

[34] D. Gupta, H. Choi, M. Y. Song, G. P. Karwasz, and J. S. Yoon, Eur. Phys. J. D 71, 88 (2017).

[35] D. Gupta, H. Choi, D. C. Kwon, J. S. Yoon, and M. Y. Song, J. Phys. D: Appl. Phys. 51, 155203 (2018).

[36] C. Szmytkowski, A. M. Krzysztofowicz, P. Janicki, and L. Rosenthal, Chem. Phys. Letts. 199, 191 (1992).

[37] G. Kasperski, P. Możejko, and C. Szmytkowski, Z. Phys. D 42, 187 (1997).

[38] C. Szmytkowski, P. Możejko, and G. Kasperski, J. Phys. B: At. Mol. Opt. Phys. 33, 15 (2000).

[39] C. Szmytkowski, S. Kwitnewski, P. Możejko, and E. P. Denga, Phys. Rev. A 66, 014701 (2002).

[40] C. Szmytkowski, E. P. Denga, and S. Kwitnewski, J. Phys. B: At. Mol. Opt. Phys. 35, 1267 (2002).

[41] C. Szmytkowski and S. Kwitnewski, J. Phys. B: At. Mol. Opt. Phys. 36, 2129 (2003).

[42] C. Szmytkowski and S. Kwitnewski, J. Phys. B: At. Mol. Opt. Phys. 36, 4865 (2003).

[43] W. M. Ariyasinghe, Rad. Phys. Chem. 68, 79 (2003).

[44] R. Panajotovic, M. Jelisavcic, R. Kajita, T. Tanaka, M. Kitajima, H. Cho, H. Tanaka, and S. J. Buckman, J. Chem. Phys. 121, 4559 (2004).

[45] M. Hoshino, P. Limão-Vieira, K. Anzai, H. Kato, H. Cho, D. Mogi, T. Tanioka, F. Ferreira da Silva, D. Almeida, F. Blanco, G. Garcia, O. Ingolfsson, and H. Tanaka, J. Chem. Phys. 141, 124302
(2014).

[46] P. T. Lan and B. H. Jeon, J. Korean Phys. Soc. 64, 1320 (2014).

[47] J. E. Sanabia, G. D. Cooper, J. A. Tossell, and J. H. Moore, J. Chem. Phys. 108, 389 (1998).

[48] O. Sueoka, C. Makochekanwa, and H. Kawate, Nucl. Instrum. Meth. B 192, 206 (2002).

[49] C. Makochekanwa, M. Kimura, and O. Sueoka, Phys. Rev. A 68, 032707 (2003).

[50] C. Makochekanwa, H. Kato, M. Hoshino, H. Cho, M. Kimura, O. Sueoka, and H. Tanaka, Eur. Phys. J. D 35, 249 (2005).

[51] C. Makochekanwa, O. Sueoka, M. Kimura, M. Kitajima, and H. Tanaka, Phys. Rev. A 71, 032717 (2005).

[52] C. Makochekanwa, M. Kimura, and O. Sueoka, Phys. Rev. A 70, 022702 (2004).

[53] C. Szmytkowski and P. Możejko, Eur. Phys. J. D 74, 90 (2020).

[54] I. Rozum, P. Limao-Vieira, S. Eden, and J. Tennyson, J. Phys. Chem. Ref. Data 35, 267 (2006).

[55] C. Winstead and V. Mckoy, J. Chem. Phys. 116, 1380 (2002).

[56] C. Winstead and V. Mckoy, J. Chem. Phys. 114, 7407 (2001).

[57] M. T. do N. Varella, A. P. P. Natalense, M. H. F. Bettega, and M. A. P. Lima, Phys. Rev A 60, 3684 (1999).

[58] C. S. Trevisan, A. E. Orel, and T. N. Rescigno, Phys. Rev. A 68, 062707 (2003).

[59] A. Sakaamini, B. Hlousek, S. M. Khakoo, M. Zawadzki, M. A. Khakoo, M. B. Kiataki, and M. H. F. Bettega, J. Phys. B: At. Mol. Opt. Phys. 52, 025206 (2019).

[60] D. Gupta, H. Choi, D. C. Kwon, J. S. Yoon, B. Antony, and M. Y. Song, J. Phys. B: At. Mol. Opt. Phys. 50, 085202 (2017).

[61] D. Gupta, H. Choi, M. Y. Song, K. Chakrabarti, and J. S. Yoon, Eur. Phys. J. D 71, 213 (2017).

[62] D. Gupta, M. Y. Song, K. L. Baluja, H. Choi, and J. S. Yoon, Phys. Plasmas 25, 063504 (2018).

[63] A. Bharadvaja, S. Kaur, and K. L. Baluja, Phys. Plasmas 26, 063506 (2019).

[64] B. Goswami and B. Antony, RSC Adv. 4, 30953 (2014).

[65] J. D. Mantilla, N. Gariboldi, S. Grob, and M. Claessens, IEEE Electrical Insulation Conference (Philadelphia, PA, USA, June 8-11, 2014) pp. 469-473.

[66] X. Zhang, Y. Li, S. Xiao, J. Tang, S. Tian, and Z. Deng, Environ. Sci. Technol. 51, 10127 (2017).

[67] J. C. Devins, IEEE Trans. Dielectr. Electr. Insul. 15, 81 (1980).

[68] X. Yu, H. Hou, and B. Wang, J. Comput. Chem. 38, 721 (2017).

[69] N. Sinha, V. M. Patel, and B. Antony, J. Phys. B: At. Mol. Opt. Phys. 53, 145101 (2020).

[70] Y. Wang, S. Tian, X. Zhang, W. Liu, Y. Wang, and G. Zhang, AIP Adv. 10, 035217 (2020).

[71] J. Xiong, X. Li, J. Wu, X. Guo, and H. Zhao, J. Phys. D: Appl. Phys. 50, 445206 (2017).

[72] L. G. Christophorou, J. K. Olthoff, and M. V. V. S. Rao, J. Phys. Chem. Ref. Data 25, 1341 (1996).

[73] L. G. Christophorou and J. K. Olthoff, J. Phys. Chem. Ref. Data 27, 1 (1998).

[74] L. G. Christophorou and J. K. Olthoff, J. Phys. Chem. Ref. Data 28, 967 (1999).

[75] L. G. Christophorou and J. K. Olthoff, J. Phys. Chem. Ref. Data 27, 889 (1998).

[76] L. G. Christophorou and J. K. Olthoff, J. Phys. Chem. Ref. Data 30, 449 (2001). 
[77] L. G. Christophorou and J. K. Olthoff, J. Phys. Chem. Ref. Data 29, 267 (2000).

[78] J. S. Yoon, M. Y. Song, H. Kato, M. Hoshino, H. Tanaka, M. J. Brunger, S. J. Buckman, and H.Cho, J. Phys. Chem. Ref. Data 39, 033106 (2010).

[79] H. Cho, J. S. Yoon, and M. Y. Song, Fusion Sci. Technol. 63, 349 (2013).

[80] K. Bartschat and M. J. Kushner, Proc. Nat. Acad. Sci. 113, 7026 (2016).

[81] P. A. Kendall, N. J. Mason, G. A. Buchanan, G. Marston, P. Tegeder, A. Dawes, S. Eden, P. Limao-Vieira, and D. A. Newnham, Chem. Phys. 287, 137 (2003).

[82] P. G. Burke, R-matrix Theory of Atomic Collisions (Springer Science \& Business Media, Berlin, 2011).

[83] J. Tennyson, Phys. Rep. 491, 29 (2010).

[84] K. Takatsuka and V. McKoy, Phys. Rev. A 24, 2473 (1981).

[85] B. I. Schneider and T. N. Rescigno, Phys. Rev. A 37, 3749 (1988).

[86] T. Meltzer, J. Tennyson, Z. Masin, M. C. Zammit, and L. H. Scarlett, J. Phys. B: At. Mol. Opt. Phys. 53, 145204 (2020).

[87] J. M. Carr, P. G. Galiatsatos, J. D. Gorfinkiel, A. G. Harvey, M. A. Lysaght, D. Madden, Z. Mašín, M. Plummer, J. Tennyson, and H. N. Varambhia, Eur. Phys. J. D 66, 58 (2012).

[88] J. Tennyson, D. B. Brown, J. Munro, I. Rozum, H. N. Varambhia, and N. Vinci, J. Phys.: Conf. Ser. 86, 012001 (2007).

[89] D. Gupta, H. Choi, M.Y. Song, S. Singh, B. Antony, K. Chakrabarti, J.S. Yoon, and J. Tennyson, J. Phys. B: At. Mol. Opt. Phys. 53, 225203 (2020).

[90] S. Singh, D. Gupta, B. Antony, M. Tudorovskaya, and J. Tennyson, J. Phys. Chem. A 124, 7088 (2020).

[91] D. Gupta, M. Y. Song, H. Choi, D. C. Kwon, K. L. Baluja, and J. Tennyson, J. Phys. B: At. Mol. Opt. Phys. 52, 065204 (2019).

[92] S. Singh, D. Gupta, and B. Antony, Plasma Sources Sci. Technol. 27, 105014 (2018).

[93] S. Singh, D. Gupta, and B. Antony, J. App. Phys. 124, 034901 (2018).

[94] P. Verma, S. Singh, R. Naghma, and B. Antony, Eur. Phys. J. D 72, 207 (2018).

[95] D. Gupta, K. Chakrabarti, M. Y. Song, and J. S. Yoon, Phys. Plasmas 24, 123511 (2017).

[96] D. Gupta, H. Choi, M. Y. Song, and J. S. Yoon, Chem. Phys. Letts. 684, 333 (2017).

[97] D. Gupta, R. Naghma, B. Goswami, and B. Antony, RSC Adv. 4, 9197 (2014).

[98] J. Kaur, B. Goswami, D. Gupta, and B. Antony, Phys. Rev. A 90, 012711 (2014).

[99] B. Goswami, D. Gupta, and B. Antony, J. Electron Spectrosc. Relat. Phenom. 193, 86 (2014).

[100] A. Barot, D. Gupta, M. Vinodkumar, and B. Antony, Phys. Rev. A 87, 062701 (2013).

[101] D. Gupta, R. Naghma, M. Vinodkumar, and B. Antony, J. Electron Spectrosc. Relat. Phenom. 191, 71 (2013).

[102] A. M. Arthurs and A. Dalgarno, Proc. Phys. Soc., London, Sect. A 256, 540 (1960).

[103] A. Faure, J. D. Gorfinkiel, L. A. Morgan, and J. Tennyson, Comput. Phys. Commun. 144, 224 (2002).

[104] M. Gailitis, J. Phys. B: At. Mol. Phys. 9, 843 (1976).

[105] N. Sanna and F. A. Gianturco, Comput. Phys. Commun. 114, 142 (1998).

[106] J. Tennyson and C. Noble, Comput. Phys. Commun. 33, 421
(1984).

[107] G. Breit and E. Wigner, Phys. Rev. 49, 519 (1936).

[108] D. Gupta, R. Naghma, and B. Antony, Can. J. Phys. 91, 744 (2013).

[109] J. Kaur, D. Gupta, R. Naghma, D. Ghoshal, and B. Antony, Can. J. Phys. 93, 617 (2015).

[110] S. Singh, S. Dutta, R. Naghma, and B. Antony, J. Phys. Chem. A 120, 5685 (2016).

[111] S. Singh, R. Naghma, J. Kaur, and B. Antony, Eur. Phys. J. D 72, 69 (2018).

[112] S. Singh, A. Sen, and B. Antony, Int. J. Mass Spectrom. 428, 22 (2018).

[113] S. Singh, A. Sen, and B. Antony, Chem. Phys. Lett. 692, 242 (2018).

[114] N. Sinha, S. Singh, and B. Antony, J. Phys. B: At. Mol. Opt. Phys. 51, 015204 (2018).

[115] D. Gupta and B. Antony, J. Electron Spectrosc. Relat. Phenom. 186, 25 (2013).

[116] R. Naghma, D. Gupta, and B. Antony, J. Electron Spectrosc. Relat. Phenom. 193, 48 (2014).

[117] R. Naghma, D. Gupta, B. Goswami, and B. Antony, Int. J. Mass Spectrom. 360, 39 (2014).

[118] D. Gupta, R. Naghma, and B. Antony, Mol. Phys. 112, 1201 (2014).

[119] D. Gupta and B. Antony, Mol. Phys. 112, 1816 (2014).

[120] D. Gupta and B. Antony, J. Chem. Phys. 141, 054303 (2014).

[121] D. Gupta, R. Naghma, and B. Antony, AIP Adv. 5, 097159 (2015).

[122] J. Kaur, S. Singh, and B. Antony, Mol. Phys. 113, 3883 (2015).

[123] P. Modak, S. Singh, J. Kaur, and B. Antony, Int. J. Mass Spectrom. 409, 1 (2016).

[124] S. Singh and B. Antony, Phys. Plasmas 25, 053503 (2018).

[125] S. N. Nahar and B. Antony, Atoms 8, 29 (2020).

[126] H. L. Cox and R. A. Bonham, J. Chem. Phys. 47, 2599 (1967).

[127] S. Hara, J. Phys. Soc. Japan 22, 710 (1967).

[128] X. Zhang, J. Sun, and Y. Liu, J. Phys. B: At. Mol. Opt. Phys. 25, 1893 (1992).

[129] G. Staszewska, D. W. Schwenke, D. Thirumalai, and D. G. Truhlar, Phys. Rev. A 28, 2740 (1983).

[130] C. J. Joachain, Quantum Collision Theory (North-Holland, 1983).

[131] R. Naghma, B. N. Mahato, M. Vinodkumar, and B. K. Antony, J. Phys. B: At. Mol. Opt. Phys. 44, 105204 (2011).

[132] M. Vinodkumar, K. Korot, and P. C. Vinodkumar, Eur. Phys. J. D 59, 379 (2010).

[133] S. Singh, R. Naghma, J. Kaur, and B. Antony, J. Chem. Phys. 145, 034309 (2016).

[134] D. Gupta, H. Choi, S. Singh, P. Modak, B. Antony, D. C. Kwon, M. Y. Song, and J. S. Yoon, J. Chem. Phys. 150, 064313 (2019).

[135] G. P. Karwasz, P. Mozejko, and M. Y. Song, Int. J. Mass Spectrom. 365, 232 (2014).

[136] A. Gauf, C. Navarro, G. Balch, L. R. Hargreaves, M. A. Khakoo, C. Winstead, and V. McKoy, Phys. Rev. A 87, 012710 (2013).

[137] C. Szmytkowski and S. Kwitnewski, J. Phys. B: At. Mol. Opt. Phys. 35, 3781 (2002).

[138] http://physics.nist.gov/RhysRefData/Ionization/MolTable.html (accessed Oct. 22, 2020).

[139] M. J. Frisch, G. W. Trucks, H. B. Schlegel, G. E. Scuseria, M. A. Robb, J. R. Cheeseman, G. Scalmani, V. Barone, G. A. Petersson, H. Nakatsuji, et al., Gaussian 09, Revision D.01, Gaussian, Inc., Wallingford CT, 2013. 